\title{
Genetic determinants of obesity heterogeneity in type II diabetes
}

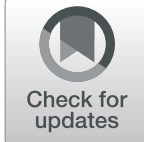

\author{
Somayeh Alsadat Hosseini Khorami ${ }^{1}$, Mohd Sokhini Abd Mutalib ${ }^{1}$, Mohammad Feili Shiraz ${ }^{2}$, \\ Joseph Anthony Abdullah ${ }^{3}$, Zulida Rejali ${ }^{4}$, Razana Mohd Ali ${ }^{5}$ and Huzwah Khaza'ai ${ }^{6 *}$
}

\begin{abstract}
Background: Although obesity is considered as the main cause of Type II diabetes (T2DM), non-obese individuals may still develop T2DM and obese individuals may not.

Method: The mRNA expression of PI3KAKT axis from 100 non-obese and obese participants with insulin sensitivity and insulin resistance states were compared in this study toward the understanding of obesity heterogeneity molecular mechanism.

Result: In present study, there was no statistically significant difference in gene expression levels of IRS1 and PTEN between groups, whereas PI3K, AKT2 and GLUT4 genes were expressed at a lower level in obese diabetic group compared to other groups and were statistically significant. PDK1 gene was expressed at a higher level in nonobese diabetic group compared to obese diabetic and non-obese non-diabetics groups. No statistically significant difference was identified in gene expression pattern of PIJKAKT pathway between obese non-diabetics and nonobese non-diabetics.

Conclusion: The components of PIBKJAKT pathway which is related to the fasting state, showed reduced expression in obese diabetic group due to the chronic over-nutrition which may induced insensitivity and reduced gene expression. The pathogenesis of insulin resistance in the absence of obesity in non-obese diabetic group could be due to disturbance in another pathway related to the non-fasting state like gluconeogenesis. Therefore, the molecular mechanism of insulin signalling in non-obese diabetic individuals is different from obese diabetics which more investigations are required to study insulin signalling pathways in greater depth, in order to assess nutritional factors, contribute to insulin resistance in obese diabetic and non-obese diabetic individuals.
\end{abstract}

Keywords: Obesity paradox, PI3KAKT pathway, PDK1, Non-obese diabetic, Type II diabetes, Gene expression, RT-PCR

\section{Introduction}

The relationship between insulin resistance and obesity is well recognised while the responsible mechanisms of obesity-related insulin resistance remain poorly understood [1-3]. Even though obesity involves enhanced risk for development of diabetes, there are some paradoxes in relationships between diabetes and obesity and no

\footnotetext{
* Correspondence: huzwah@upm.edu.my

${ }^{6}$ Department of Biomedical Science, University Putra Malaysia, 43400 Serdang, Selangor, Malaysia

Full list of author information is available at the end of the article
}

unifying hypothesis has been proposed to explain these paradoxical phenomena. It cannot be ruled out that, 15\% of diabetic individuals in North America and $50 \%$ of them in Europe are non-obese $(\mathrm{BMI}<30)$ diabetic. Also, more than $60 \%$ of diabetic individuals in Asia are nonobese even while the obesity criteria for Asia was adjusted from BMI > 30 to $\mathrm{BMI}>27.5$ [4]. Therefore, other factors besides or instead of obesity may contribute to development of non-obese Type II diabetes.

Recent progress in research methodology on signaling pathways has identified the insulin signal transduction

(c) The Author(s). 2020 Open Access This article is licensed under a Creative Commons Attribution 4.0 International License, which permits use, sharing, adaptation, distribution and reproduction in any medium or format, as long as you give appropriate credit to the original author(s) and the source, provide a link to the Creative Commons licence, and indicate if changes were made. The images or other third party material in this article are included in the article's Creative Commons licence, unless indicated otherwise in a credit line to the material. If material is not included in the article's Creative Commons licence and your intended use is not permitted by statutory regulation or exceeds the permitted use, you will need to obtain permission directly from the copyright holder. To view a copy of this licence, visit http://creativecommons.org/licenses/by/4.0/ The Creative Commons Public Domain Dedication waiver (http://creativecommons.org/publicdomain/zero/1.0/) applies to the data made available in this article, unless otherwise stated in a credit line to the data. 
and documented its alterations in insulin-resistance state [5-7]. Insulin-stimulated glucose transport occurs via PI3K/AKT-dependent pathway (Phosphatidylinositol 3kinase/Protein Kinase B) which results in GLUT4 (Glucose Transporter 4) translocation to the plasma membrane to mediate glucose uptake and activation of glycogen synthase [8]. By stimulation of insulin, PI3K phosphorylates membrane phospholipids and converts PIP2 (Phosphotidylinositol-4,5-bisphosphate) to PIP3 (Phosphotidylinositol-3,4,5-triphosphate). This complex phosphorylates/activates the PDK1 and PDK2 (PhosphoinositideDependent Kinase) leading to activation of $A K T / P K B$ and $P K C$ (Protein Kinase $C$ ) phosphorylation to translocate GLUT4 to the plasma membrane from intracellular vesicular compartment [9]. PI3K/AKT pathway can be reversely dephosphorylated by PTEN phosphatase (Phosphatase and TENsin homolog deleted on chromosome 10) through converting PIP3 back to PIP2 [10]. All these events are related to short-term post-translational regulation of protein functions and long-term transcriptional regulation [11].

Insulin resistance in Type II diabetes has been characterized by several defects in the insulin signaling cascade $[8$, 12-14]. This hypothesis is supported by findings of altered expression of genes encoding metabolic pathways in Type II diabetic patients [15] such as, insulin-induced activity of IR, IRS, PISK, AKT and GLUT4 have been reported to be reduced in Type II diabetes [16-19]. Understanding of these alterations may explain the heterogeneity of obesity and its manifestations. The pathogenesis of insulin resistance in absence and presence of obesity is unknown and more investigations are required to study insulin signalling pathways in greater depth to assess nutritional factors contribute to insulin resistance in non-obese diabetic and obese diabetic individuals separately.

Type II diabetes is a multifaceted disease resulting from the interaction of genetics, epigenetics, lifestyle such as diet and environmental as the contributing factors. These risk factors induce or suppress expression of genes involved in insulin signaling [20]. Nutrition plays a key role in pathogenesis of diabetes and nutrient gene interactions may modulate gene expression of insulin signaling component directly or via their metabolites [21]. Blood samples collected in the framework of gene expression and epidemiological studies allow the use of humans as the model system, as opposed to using cell lines or animal models [22].

The aim of this study was to investigate the gene expression pattern of PI3K/AKT pathway in obese and non-obese metabolically healthy individuals and compare this pattern with obese and non-obese diabetics to propose molecular mechanistic insights into how differential regulation of $P I 3 K / A K T$ pathway is responsible for obesity heterogeneity in Type II diabetes.

\section{Research design and methods}

\section{Study protocol and participants characteristics}

A total of 50 Type II diabetic and 50 non-diabetic individuals recruited in the context of a cross-sectional study on insulin signal transduction at the Universiti Putra Malaysia and Serdang Hospital. Diabetic and nondiabetic participants were divided to two groups based on category of body mass index $(\mathrm{BMI}<30$ and $\mathrm{BMI}>$ 30) to find out differences in molecular mechanism underlying regulation of $P I 3 K / A K T$ pathway. In diabetic and non-diabetic group, $50 \%$ were normal/overweight $(\mathrm{BMI}<30 \mathrm{~kg} / \mathrm{m} 2)$ and $50 \%$ were obese (BMI of $>30 \mathrm{~kg} /$ $\mathrm{m} 2$ ). This weight distribution was not significantly different between four groups. The age ranged from 35 to 60 years and there was no statistically significant difference between groups $(P>0.05)$. Participants who had cancers, nephropathy complications, thyroid \& parathyroid diseases and pregnant women were excluded from this study. Also, participants were excluded if they reported using any form of tobacco, cigarettes and alcoholic beverages. The study was approved by the ethics committee of Universiti Putra Malaysia and National Medical Research Register (NMRR \& MREC). Also, the study was conducted in accordance to the Declaration of Helsinki in its currently applicable version and the guidelines of the International Conference on Harmonization of Good Clinical Practice (ICH-GCP). All participants gave written informed consent before taking part in the study.

\section{Study design}

The mRNA expression of insulin signalling components from i) obese Type II diabetic participants (OD) and obese non-diabetics (OND), ii) non-obese Type II diabetic participants (NOD) and non-obese non-diabetics (NOND), iii) obese Type II diabetic participants (OD) and non-obese diabetics (NOD), iv) obese non-diabetic participants (OND) and non-obese non-diabetics (NOND) were compared in this study toward the understanding of obesity heterogeneity molecular mechanism.

Assessment of clinical and metabolic characteristics of participants. FBS (Cat.No:04657527) was tested by colorimetric enzymatic method using Roche Diagnostics $\mathrm{GmbH}$ Cobas-c 311 Germany machine. HbA1c analysis was performed by the colorimetric method (Diazyme; cat. No. DZ168A, USA) and C-peptide level was determined by ELISA Kit (Cloud Clone Corp; cat. no. CEA447Hu, UK).

\section{Gene expression analysis}

Blood samples were collected after an overnight fast. Total RNA was isolated by using PAXgene Blood RNA Tubes (Qiagen; cat. no. 762165) according to the manufacturer protocol and it was converted to cDNA by using the Qiagen cDNA Synthesis Kit (Qiagen; cat. no. 205313). Real time PCR (RT-PCR) reactions were performed by using 
SYBR green technology and QuantiTect Rev. Transcription Kit (Qiagen; cat. no. 205313, Germany). The final volume of the RT-PCR reaction mixture was $20 \mu \mathrm{l}$ and contained $2 \mu \mathrm{cDNA}, 1 \mu \mathrm{M}$ of each primer, $10 \mu \mathrm{l}$ Master Mix and RNase-free water up to $20 \mu \mathrm{l}$. RNA concentration and purity were measured by using a Nano Drop ND1000 spectrophotometer at A260:A280 ratio (Thermo Fisher Scientific; USA). RNA quality and integrity were determined via agarose gel electrophoresis. A positive control containing all the components of the reaction in except of template and a negative control containing template without reverse transcriptase were used to ensure quality of run and confirm the absence of contamination. RT-PCR was performed on a Bio-Rad cycler (Bio-Rad; CFX96, USA) and cycling conditions were as follows: $95^{\circ} \mathrm{C}$ for $5 \mathrm{~min}$ (PCR initial activation step); $95^{\circ} \mathrm{C}$ for $10 \mathrm{~s}$ (denaturation); $60^{\circ} \mathrm{C}$ for $30 \mathrm{~s}$ (combined annealing/extension); followed by 40 cycles.

Real-time PCR results were calculated according to the $\triangle \triangle C T$ method by using GAPDH and $\beta$-ACTIN as housekeeping genes.

\section{Statistical analyses}

Each experiment was performed triplicate and all data were expressed as means \pm SE. Statistical analysis was performed by using SPSS 21.0 statistical software package (SPSS Inc., Chicago, IL, USA). The univariate normality assumptions were verified with the ShapiroWilk test. Independent-samples t-test was applied to compare the means between two groups and threshold of significance was defined as a $P<0.05$.

\section{Results}

Clinical and metabolic characteristic data of participants involved in this study is summarised in Table 1.

Although the PI3K/AKT pathway is responsible for glucose uptake from blood stream to the target cells, the underlying mechanism has not been clarified yet. In current study, gene expression pattern of the components of this pathway has been identified and compared among the participants based on obesity and insulin sensitivity state, as demonstrated in Tables 2, 3, 4 and 5.
PI3K, AKT2 and GLUT4 expression levels were significantly lower in obese diabetic participants compared to obese non-diabetics. PDK1 expression level was significantly higher in non-obese diabetic participants compared to non-obese non-diabetics. The obese diabetic and non-obese diabetic groups were significantly different based on PI3K, AKT2, GLUT4 and PDK1 gene expression levels. The gene expression levels of $P I 3 K$, $A K T 2$ and GLUT4 were significantly lower in obese diabetic participants compared to non-obese diabetics whereas the gene expression level of PDK1 was significantly higher in non-obese diabetics compared to obese diabetics. No statistically significant gene expression difference was identified between non-obese non-diabetics and obese non-diabetics.

These results provide evidence that non-obese diabetics might be different from obese diabetics, also obese diabetics might be different from obese non-diabetics in mechanism of insulin signal transduction which causes obesity heterogeneity.

Expression levels of PI3K, AKT2 and GLUT4 were significantly lower in obese Type II diabetic participants in comparison to the obese non-diabetics.

There was no significant difference in gene expression pattern of PI3K/AKT pathway between non-obese diabetic and non-obese non-diabetics in except of higher expression level of $P D K 1$ in non-obese diabetics.

The gene expression levels of PI3K, AKT2 and GLUT4 were significantly lower in obese diabetic participants compared to non-obese diabetics whereas the gene expression level of PDK1 was significantly higher in non-obese diabetics.

The non-obese non-diabetic and obese non-diabetic groups were not significantly different based on PI3K/ $A K T$ pathway genes.

Likewise, there was no difference in the trends of the data when men and women were analysed separately.

\section{Discussion}

The main strength of this study is the inclusion of nonobese and obese participants with insulin sensitivity and insulin resistance states. This study design allowed for a

Table 1 Clinical and Metabolic Characteristic Data of Participants

\begin{tabular}{|c|c|c|c|c|}
\hline Study Variables & $\begin{array}{l}\mathrm{OD}(\boldsymbol{n}=25) \\
\text { Mean } \pm \mathrm{SE}\end{array}$ & $\begin{array}{l}\mathrm{NOD}(\boldsymbol{n}=25) \\
\text { Mean } \pm \mathrm{SE}\end{array}$ & $\begin{array}{l}\text { OND }(\boldsymbol{n}=25) \\
\text { Mean } \pm \text { SE }\end{array}$ & $\begin{array}{l}\text { NOND }(\boldsymbol{n}=25) \\
\text { Mean } \pm \text { SE }\end{array}$ \\
\hline Age & $50.84 \pm 1.54$ & $55.28 \pm 1.89$ & $47.53 \pm 1.97$ & $45.78 \pm 1.57$ \\
\hline Female (\%) & 52 & 48 & 52 & 48 \\
\hline BMI & $35.71 \pm 1.90$ & $28.68 \pm 0.78$ & $33.55 \pm 1.01$ & $27 . \pm 1.38$ \\
\hline FBS $(\mathrm{mmol} / \mathrm{L})$ & $8.19 \pm 0.14$ & $8.57 \pm 0.17$ & $5.51 \pm 0.08$ & $5.28 \pm 0.11$ \\
\hline HbA1c (\%) & $8.05 \pm 0.14$ & $7.79 \pm 0.40$ & $5.57 \pm 0.71$ & $5.14 \pm 0.35$ \\
\hline C-Peptide (ng/mL) & $1.96 \pm 0.03$ & $1.97 \pm 0.01$ & $2.00 \pm 0.02$ & $2.04 \pm 0.04$ \\
\hline
\end{tabular}

$O D$ obese diabetic participants, OND obese non-diabetics, NOD non-obese Type II diabetic participants, NOND non-obese non-diabetics 
Table 2 Relative Expression Levels for GOls between Obese Diabetic and Obese Non-Diabetic Participants

\begin{tabular}{llllll}
\hline GOls & $\begin{array}{l}\text { OD }(\boldsymbol{n}=25) \\
\text { Mean } \pm \text { SE }\end{array}$ & $\begin{array}{l}\text { OND }(\boldsymbol{n}=25) \\
\text { Mean } \pm \text { SE }\end{array}$ & df & t & P-value \\
\hline IRS1 & $0.23 \pm 0.01$ & $0.26 \pm 0.02$ & 48 & -0.96 & 0.342 \\
PI3K & $0.53 \pm 0.03$ & $0.32 \pm 0.03$ & 48 & 4.03 & $0.001^{*}$ \\
PDK1 & $0.63 \pm 0.05$ & $0.68 \pm 0.08$ & 48 & -1.27 & 0.757 \\
AKT2 & $1.14 \pm 0.08$ & $0.65 \pm 0.07$ & 48 & 3.39 & $0.001^{*}$ \\
GLUT4 & $1.13 \pm 0.11$ & $0.79 \pm 0.08$ & 48 & 2.27 & $0.028^{*}$ \\
PTEN & $0.42 \pm 0.04$ & $0.46 \pm 0.04$ & 48 & -0.74 & 0.463
\end{tabular}

All data was expressed in percentage and mean \pm standard deviation (SD). *Significant level is at $0.05 p$-value

simultaneous investigation on the influence of obesity and diabetes on PI3K/AKT pathway toward the identification of genetic determinants of obesity heterogeneity in Type II diabetes. Consideration of only PI3K/AKT axis of insulin signalling pathways limited interpretations to this study.

Even though other biochemical and physiological differences may exist between OD and NOD group beyond their BMI, the results of this study suggest that the gene expression pattern of PI3K/AKT pathway in NOD group is more closely resemble to the gene expression pattern of OND and NOND groups and differs from OD group. Indeed, significant higher gene expression level of $P D K 1$ in NOD group compared to other groups emphasizes disturbance in another signaling pathway in NOD individuals.

Therefore, it can be hypothesized that insulin resistance and obesity might be distinct risk factors for metabolic disturbances [23]. Furthermore, it has been revealed that the presence of obesity does not necessarily cause alterations in PI3K/AKT pathway gene expression and insulin resistance and Type II diabetes is not necessarily associated with obesity and alterations in PI3K/AKT pathway gene expression. However, this study has revealed that disturbed PI3K/AKT pathway genes expression was associated with obesity and insulin resistance. Classification of

Table 3 Relative Expression Levels for GOls between NonObese Diabetic and Non-Obese Non-Diabetic Participants

\begin{tabular}{llllll}
\hline GOls & $\begin{array}{l}\text { NOD }(\boldsymbol{n}=25) \\
\text { Mean } \pm \text { SE }\end{array}$ & $\begin{array}{l}\text { NOND }(\boldsymbol{n}=25) \\
\text { Mean } \pm \text { SE }\end{array}$ & df & t & $P$-value \\
\hline IRS1 & $0.20 \pm 0.02$ & $0.20 \pm 0.02$ & 48 & -0.28 & 0.774 \\
PI3K & $0.38 \pm 0.03$ & $0.32 \pm 0.03$ & 48 & 1.26 & 0.212 \\
PDK1 & $0.51 \pm 0.04$ & $0.70 \pm 0.07$ & 48 & -2.40 & $0.001^{*}$ \\
AKT2 & $0.57 \pm 0.05$ & $0.70 \pm 0.06$ & 48 & -1.59 & 0.115 \\
GLUT4 & $0.79 \pm 0.08$ & $0.69 \pm 0.07$ & 48 & 0.79 & 0.432 \\
PTEN & $0.43 \pm 0.04$ & $0.43 \pm 0.05$ & 48 & 0.02 & 0.982 \\
\hline AII
\end{tabular}

All data was expressed in percentage and mean \pm standard deviation (SD). *Significant level is at $0.05 p$-value
Table 4 Relative Expression Levels for GOls between Obese Diabetic and Non-Obese Diabetic Participants

\begin{tabular}{llllll}
\hline GOIs & $\begin{array}{l}\text { NOD }(\boldsymbol{n}=25) \\
\text { Mean } \pm \text { SE }\end{array}$ & $\begin{array}{l}\text { OD }(\boldsymbol{n}=25) \\
\text { Mean } \pm \text { SE }\end{array}$ & df & t & $P$-value \\
\hline IRS1 & $0.20 \pm 0.02$ & $0.23 \pm 0.01$ & 48 & -1.04 & 0.299 \\
PI3K & $0.38 \pm 0.03$ & $0.53 \pm 0.03$ & 48 & -2.97 & $0.005^{*}$ \\
PDK1 & $0.51 \pm 0.02$ & $0.63 \pm 0.05$ & 48 & -4.93 & $0.001^{*}$ \\
AKT2 & $0.57 \pm 0.05$ & $1.14 \pm 0.09$ & 48 & -4.59 & $0.001^{*}$ \\
GLUT4 & $0.79 \pm 0.08$ & $1.13 \pm 0.11$ & 48 & -2.33 & $0.024^{*}$ \\
PTEN & $0.43 \pm 0.04$ & $0.42 \pm 0.04$ & 48 & 0.26 & 0.792 \\
\hline
\end{tabular}

All data was expressed in percentage and mean \pm standard deviation (SD). *Significant level is at $0.05 p$-value

obesity into metabolically healthy obesity and metabolically unhealthy obesity can also be explained by this hypothesis. Insulin resistance occurs when obesity is accompanied by reduced gene expression of PI3K/AKT2/ GLUT4 pathway. An obese individual with a normal PI3K/AKT2/GLUT4 gene expression level would be still metabolically healthy until the time body is not able to keep this ability. Another assumption is that their adipocytes are able to switch from glucose to fatty acid metabolism which may be beneficial in combating metabolic syndrome [24] or the combination of their diet is different from OD group which further details will be discussed. Also, it has been reported that there is no significant differences in BMI, waist circumferences and fat mass between European NOD and control individuals [25], hence, visceral fat is not associated with non-obese diabetes. Since, insulin resistance is not associated with obesity and alterations in PI3K/AKT pathway in NOD individuals, disturbances in other insulin signalling pathways are proposed.

Two major downstream pathways of insulin action are the PI3K/AKT (phosphatidylinositol 3-kinase/protein kinase $\mathrm{B}$ ) and $M A P K$ (mitogen-activated protein kinases) pathways [26, 27]. In this study the $P I 3 K / A K T$ pathway has been considered which is related to the fasting state, hence the components of this pathway showed alterations

Table 5 Relative Expression Levels for GOls between Obese Non-Diabetic and Non-Obese Non-Diabetics Participants

\begin{tabular}{llllll}
\hline GOls & $\begin{array}{l}\text { NOND }(\boldsymbol{n}=25) \\
\text { Mean } \pm \text { SE }\end{array}$ & $\begin{array}{l}\text { OND }(\boldsymbol{n}=25) \\
\text { Mean } \pm \text { SE }\end{array}$ & df & t & $P$-value \\
\hline IRS1 & $0.20 \pm 0.02$ & $0.26 \pm 0.02$ & 48 & -1.54 & 0.130 \\
PI3K & $0.32 \pm 0.03$ & $0.32 \pm 0.03$ & 48 & -0.10 & 0.914 \\
PDK1 & $0.70 \pm 0.07$ & $0.68 \pm 0.08$ & 48 & -0.13 & 0.897 \\
AKT2 & $0.70 \pm 0.06$ & $0.65 \pm 0.06$ & 48 & 0.45 & 0.654 \\
GLUT4 & $0.69 \pm 0.07$ & $0.79 \pm 0.08$ & 48 & -0.85 & 0.395 \\
PTEN & $0.43 \pm 0.04$ & $0.46 \pm 0.05$ & 48 & -0.42 & 0.674
\end{tabular}

All data was expressed in percentage and mean \pm standard deviation (SD). Significant level is at $p$-value $<\mathbf{0 . 0 5}$. 
in OD group as a result of over nutrition. Over-stimulated $P I 3 K / A K T$ pathway due to the chronic over-nutrition may induced insensitivity. This "overstimulation-induced insensitivity" phenomenon is commonly present in almost all of the metabolic disorders [28] which may cause reduced gene expression level in PI3K/AKT pathway in OD group. Therefore, pathogenesis of insulin resistance in the absence of obesity in NOD individuals could be related to other pathways of insulin signaling $[29,30]$.

The findings of present study showed reduced expression level of PISK, AKT2 and GLUT4 in OD group compared to other groups. Nevertheless, there was no significant difference in gene expression level of PTEN and IRS1 in OD, NOD, OND and NOND groups.

No significant difference in IRS1 expression level might be due to the collaboration of various mechanisms including signal amplification as a compensatory mechanism and convergence of other signalling pathways. However, the role of negative feedback loops cannot be neglected, as control of insulin signalling can be achieved by autoregulation whereby downstream elements inhibit upstream components [31,32].

It has been documented that overexpression of PTEN decreases insulin-stimulated PI3K/AKT pathway, GLUT4 translocation and glucose uptake into the cells $[18,33]$. Microinjection of anti-PTEN antibody increases insulinstimulated GLUT4 translocation to the cell membrane and glucose uptake [33]. No significant difference in PTEN expression level might be related to the collaboration or interaction of PTEN with other phosphatases in antagonizing PI3K/AKT pathway and induction of diabetes. Therefore, further studies are required to differentiate the roles of different phosphatases, their interactions and collaborations. Since the main role of PTEN is performed by dephosphorylating the stimulated form of insulin receptor and modulating post-receptor signalling through converting PIP3 back into PIP2 and reversing the effects of PI3K/ $A K T$ pathway [34-36], its transmembrane function might be more imperative than its intracellular function [37-39].

Although MAPK insulin signalling pathway was not investigated in this study, previous data from researchers [40] support the idea that alterations in MAPK signal transduction contributes to development of Type II diabetes as well. The coordinated regulation of glucose uptake from circulation and endogenous glucose production is indispensable to maintain constant blood glucose level. The liver contributes to this process through controlling the gluconeogenesis and glycogenolysis. Suppression of endogenous glucose production during the postprandial state is attributed to insulin. Moreover, insulin activates glycogen synthase while simultaneously inactivates phosphorylase a and phosphorylase kinase to control glycogen metabolism through the $M A P K$ pathway [27]. Mice lacking $M A P K$ phosphatase-1 exhibited hepatic insulin resistance and increased gluconeogenesis [41]. Thus, transcriptional regulation of key gluconeogenic genes (Glucose-6-phosphatase, Pyruvate carboxylase and PEP carboxykinase) is as important as glucose metabolism genes (PI3K/AKT pathway components). Transcription factor FOX01, has been identified as a main regulator of gluconeogenesis [42]. In the fed state, insulin signaling activates PI3K/AKT axis and subsequently phosphorylates/inactivates FOXO1 to inhibit gluconeogenesis [43]. Hyperglycemia following hepatic deletion of $A K T$ could be corrected by concomitant hepatic deletion of FOX01 [43, 44]. Specific deletion of FOXO1 in the liver of mice caused reduced gluconeogenic genes expression level and fasting glucose. Also, glucose clamp studies demonstrated that FOXO1 ablation impairs fasting gluconeogenesis and glycogenolysis.

It has been known that $P K C$ is an activator of gluconeogenesis through activation of MAPK pathway [45, 46] besides stimulation of pyruvate carboxylase [47]. Activation of MAPK pathway stimulates FOXO1 axis to increase Glucose-6-phosphatase and PEP carboxykinase. $P I 3 K$ via $P D K 1$ activates $P K C$, which stimulates gluconeogenesis and contributes to insulin resistance by converting free fatty acids to Acetyl-CoA, which activates pyruvate carboxylase [47] (Fig. 1).

Consequently, the insulin regulation of endogenous and exogenous glucose metabolism and maintenance of glucose homeostasis are mediated though PI3K/AKT and $M A P K$ pathways [43]. In this case, the involvement of nutritional factors may pronounce in stimulation or inhibition of different insulin signalling pathways. A selective model of insulin resistance can be proposed to explain the paradoxical findings related to the obesity and Type II diabetes. In non-obesity insulin resistance state, there might be a selective loss of insulin function possibly through $P K C$ axis instead of $A K T(P K B)$ axis. Though, this study did not directly address the effect of $P K C$ activation on selective insulin resistance, contribution of endogenous glucose production is proposed in NOD individuals as a result of increased gene expression level of $P D K 1$ in this group which is the main regulator of $P K C$ axis. This selective model of insulin resistance might be induced by different nutritional stimulators and a combination of nutritional and hormonal model that includes multiple modes of insulin signalling pathways regulations is proposed [47]. This model can explain experimental findings and demonstrates how several feedback loops based on different nutritional stimulators can produce obesity heterogeneity. Determining nutritional mediators which stimulate different molecular mechanisms of insulin signalling to generate these paradoxical effects provides insights into the obesity heterogeneity in Type II diabetes.

It has been suggested that ketogenic diets and high glycemic index or glycemic load diets develop Type II 


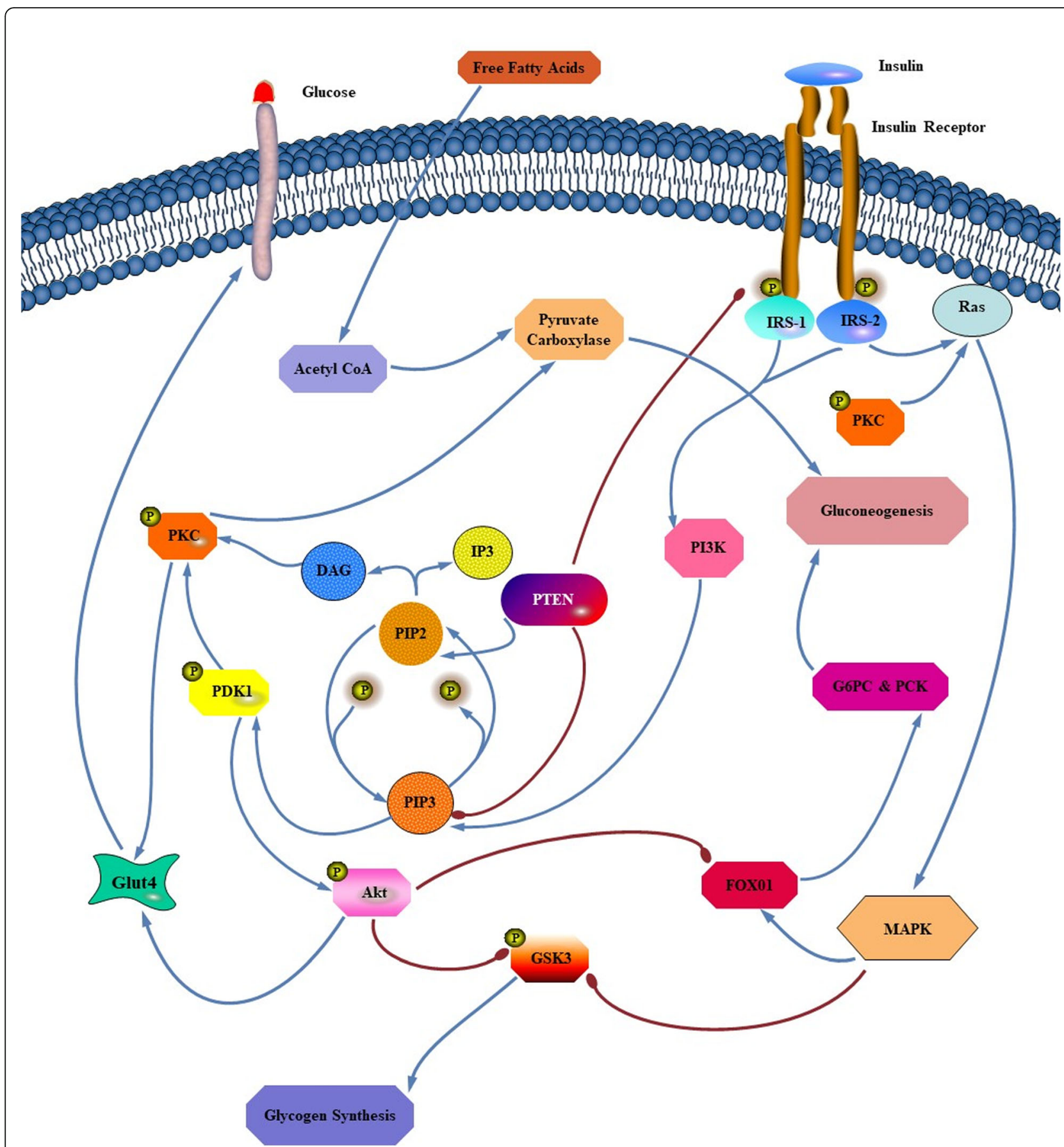

Fig. 1 Coordinated regulation of exogenous glucose uptake from circulation and endogenous glucose production through gluconeogenesis and glycogenolysis. Insulin receptors stimulate phosphorylation/activation of IRS and subsequently activation of PI3K cascade which is the main pathway involved in glucose transport. PI3K stimulates phosphorylation of AKT and GSK3, which increases and decreases their activities respectively. The function of the previously mentioned kinases of PI3KAKT pathway is antagonized by PTEN phosphatase. AKT phosphorylates/ inactivates GSK3 and increases glycogen synthase activity. Also, AKT inhibits FOXO1 which results in inhibition of gluconeogenesis by suppressing G6pc and PCK1. PI3K via PDK1 activates PKC that stimulates gluconeogenesis and contributes to insulin resistance by converting free fatty acids to Acetyl-CoA, which activates pyruvate carboxylase

diabetes through endogenous glucose production and emphasizes the role of nutritional induction for obesity paradox in diabetes. ketogenic diets induce severe hepatic insulin resistance in mice through impairments in insulin suppression of endogenous glucose production during a hyper-insulinemic 
euglycemic clamp. These researchers claimed that hepatic insulin resistance could be attributed to the increase of hepatic triglycerides and diacylglycerol content which may cause reduced insulin signalling through activation of $P K C[48,49]$. Mice lacking $P K C$ were protected from dietinduced insulin resistance, even with increased hepatic lipid content [50]. Also, gene expression of FOXO1 is increased in non-alcoholic steatohepatitis individuals that emphasizes the role of disturbed lipid metabolism in dysregulation of gluconeogenesis [51]. Contradictory findings in research of hepatic metabolism indicate distinct adaptive metabolism in starvation, ketogenic diets and fasting states.

It has been suggested that chronic exposure to high glycemic index and high glycemic load diets stimulate more production of insulin, resulting in hyper-insulinemia and insulin resistance due to the pancreas exhaustion and failure [52]. Moreover, high glycemic index and/or high glycemic load diets increase blood glucose and free fatty acids [53]. Elevated blood glucose can induce higher peak of insulin and low post-prandial glucose which may stimulate glycogenolysis and gluconeogenesis [53]. Elevated free fatty acids may stimulate gluconeogenesis through activation of $P K C$ axis [47].

Another proof of induced insulin resistance through endogenous glucose production is hyperglycemia induced by psychiatric stress that play role in pathogenesis of Type II diabetes [54]. The level of hyperglycemia induced by psychiatric stress is difficult to elucidate as it is impossible to produce and/or quantify in humans due to the ethical and methodological considerations. Glucagon, epinephrine and cortisol as stress hormones cause hyperglycemia through stimulation of gluconeogenesis and glycogenolysis in liver, inhibition of insulin secretion and interruption of glucose absorption in muscle [55-57]. It has been documented that epinephrine stimulates glucagon to produce glucose in stress situation, whereas cortisol maintains elevated glucose by epinephrine and glucagon in post-stress phase $[58,59]$.

Another molecular mechanism associated with insulin receptor regulation which is not considered in this study is $M A P K$ pathway that controls metabolism and contributes in regulation of gluconeogenesis. Therefore, the pathogenesis of insulin resistance in the absence of obesity in NOD individuals could be due to the other pathways related to the non-fasting states like gluconeogenesis. Indeed, the contribution of endogenous glucose production may have been underestimated in NOD individuals.

\section{Conclusion}

Evidently, diabetes and obesity are a complex disease with a large pool of genes that are involved in its development. It can be postulated that obesity is an independent or distinct risk factor of Type II diabetes while the impaired gene expression of different insulin signalling pathways would be the main risk factors which some of these disorders may accompany by obesity and some may not. This hypothesis offers an effective explanation for the noted paradoxes of diabetes and obesity.

In this study the PI3K/AKT pathway has been considered which is related to the fasting state, and its components showed reduced expression in obese diabetic group due to the chronic over-nutrition which may induce insensitivity and reduced gene expression level.

Although evidence of differential regulation of insulin signalling pathway based on nutritional stimulations is available, molecular mechanisms responsible for insulin resistance and obesity heterogeneity are largely speculative at this time. Future investigations are undertaken to address the question that whether nutritional mediators stimulate different molecular mechanisms of insulin signalling or endogenous glucose production is responsible for insulin resistance and these paradoxical effects for devising treatments.

\begin{abstract}
Abbreviations
AKT: Protein Kinase B; FOX01: Transcription factor; GLUT4: Glucose Transporter 4; IR: Insulin receptor; IRS: Insulin-receptor substrate; MAPK: Mitogen-activated protein kinases; NOD: Non-obese Type II diabetic; NOND: Non-obese nondiabetic; OD: Obese Type II diabetic; OND: Obese non-diabetic;

PDK: Phosphoinositide-Dependent Kinase; PI3K: Phosphatidylinositol 3-kinase; PIP2: Phosphotidylinositol-4,5-bisphosphate; PIP3: Phosphotidylinositol-3,4,5triphosphate; PKC: Protein Kinase C; PTEN: Phosphatase and TENsin homolog deleted on chromosome 10
\end{abstract}

\section{Acknowledgements}

This work was supported by the Fundamental Research Grant Scheme (grant number: 14-554-20427).

\section{Authors' contributions}

SAHK,$M^{1}$ MAM $^{1}$ and $H K^{6}$ were responsible for the study concept and design. SAHK ${ }^{1}$ and $\mathrm{JAA}^{3}$ contributed to data acquisition. MFS ${ }^{2}$ assisted $\mathrm{SAHK}^{1}$ with data analysis and interpretation of findings. SAHK ${ }^{1}$ drafted the manuscript. $\mathrm{MSAM}^{1}, \mathrm{HK}^{6}, Z^{4}$ and $\mathrm{RMA}^{5}$ provided critical revision of the manuscript for important intellectual content and approved final version for publication. All authors read and approved the final manuscript.

\section{Funding}

This work was supported by the Fundamental Research Grant Scheme (grant number: 14-554-20427).

\section{Availability of data and materials}

The data that support the findings of this study are available.

\section{Ethics approval and consent to participate}

The necessary approval was obtained from UPM ethic committee. The study was conducted in accordance to the Declaration of Helsinki in its currently applicable version, the guidelines of the International Conference on Harmonization of Good Clinical Practice (ICH-GCP) and coordination with the Health Ministry of Malaysia was fulfilled based on the applicable Malaysian laws (National Medical Research Register, (NMRR)). Consent has been obtained from each participant after full explanation of the purpose and nature of all procedures used. Ref. no: UPM/TNCPI/RMC/JKEUPM /1.4.18.1/F1.

Consent for publication

Not applicable. 


\section{Competing interests}

The authors declare that they have no competing interests.

\section{Author details}

${ }^{1}$ Department of Nutrition and Dietetic, University Putra Malaysia, 43400 Serdang, Selangor, Malaysia. ${ }^{2}$ Department of Artificial Intelligence and Computer Engineering, Faculty of Electrical Engineering, Computer and IT, Qazvin Branch, Islamic Azad University, Qazvin, Iran. ${ }^{3}$ Consultant Physician at Perak Community Hospital, Ipoh, Malaysia. ${ }^{4}$ Department of Obstetrics and Gynaecology, University Putra Malaysia, 43400 Serdang, Selangor, Malaysia. ${ }^{5}$ Department of Pathology, University Putra Malaysia, 43400 Serdang, Selangor, Malaysia. ${ }^{6}$ Department of Biomedical Science, University Putra Malaysia, 43400 Serdang, Selangor, Malaysia.

\section{Received: 21 March 2020 Accepted: 1 July 2020}

\section{Published online: 09 July 2020}

\section{References}

1. Tong Z, et al. Pancreas-specific Pten deficiency causes partial resistance to diabetes and elevated hepatic AKT signaling. Cell Res. 2009;19(6):710-9.

2. Wijesekara $\mathrm{N}$, et al. Muscle-specific Pten deletion protects against insulin resistance and diabetes. Mol Cell Biol. 2005;25(3):1135-45.

3. Delibegovic M, et al. Improved glucose homeostasis in mice with musclespecific deletion of protein-tyrosine phosphatase 1B. Mol Cell Biol. 2007; 27(21):7727-34.

4. Chuang H-C, Tan T-H. MAP 4K4 and IL-6+ Th17 cells play important roles in non-obese type 2 diabetes. J Biomed Sci. 2017;24(1):4.

5. Fragoso R, Barata JT. PTEN and leukemia stem cells. Adv Biol Regul. 2014;56:22-9.

6. Rains $\mathrm{J}$, Jain SK. Oxidative stress, insulin signaling, and diabetes. Free Radic Biol Med. 2011:50(5):567-75.

7. Manna P, Jain SK. Hydrogen sulfide and L-cysteine increase phosphatidylinositol 3,4,5-trisphosphate (PIP3) and glucose utilization by inhibiting phosphatase and tensin homolog (PTEN) protein and activating phosphoinositide 3-kinase (PI3K)/serine/threonine protein kinase (a). J Biol Chem. 2011;286(46):39848-59.

8. Wasserman DH, Ayala JE. Interaction of physiological mechanisms in control of muscle glucose uptake. Clin Exp Pharmacol Physiol. 2005;32(4):319-23.

9. Alsadat S, Khorami H, Movahedi A, Kuzwah K, Mutalib A, Sokhini M. PI3K AKT pathway in modulating glucose homeostasis and its alteration in diabetes. Ann Med Biomed Sci. 2015;1(2):46-55.

10. Leslie NR, Dixon MJ, Schenning M, Gray A, Batty $\mathbb{H}$. Distinct inactivation of PI3K signalling by PTEN and 5-phosphatases. Adv Biol Regul. 2012; 52(1):205-13.

11. O'Brien RM, Streeper RS, Ayala JE, Stadelmaier BT, Hornbuckle LA. Insulinregulated gene expression. Biochem Soc Trans. 2001;29(Pt 4):552-8.

12. Choi CS, Kim Y-B, Lee FN, Zabolotny JM, Kahn BB, Youn JH. Lactate induces insulin resistance in skeletal muscle by suppressing glycolysis and impairing insulin signaling. Am J Physiol Endocrinol Metab. 2002;283(2):E233-40.

13. Frangioudakis G, Ye J-M, Cooney GJ. Both saturated and n-6 polyunsaturated fat diets reduce phosphorylation of insulin receptor substrate-1 and protein kinase B in muscle during the initial stages of in vivo insulin stimulation. Endocrinology. 2005;146(12):5596-603.

14. Singh LP, Gennerette D, Simmons S, Crook ED. Glucose-induced insulin resistance of phosphatidylinositol 3'-OH kinase and AKT/PKB is mediated by the hexosamine biosynthesis pathway. J Diabetes Complicat. 15(2):88-96.

15. Carlsson P, Mahlapuu M. Forkhead transcription factors: key players in development and metabolism. Dev Biol. 2002;250(1):1-23.

16. Chen $\mathrm{D}$, et al. p50alpha/p55alpha phosphoinositide 3-kinase knockout mice exhibit enhanced insulin sensitivity. Mol Cell Biol. 2004;24(1):320-9

17. Leslie NR, Downes CP. PTEN: the down side of PI 3-kinase signalling. Cell Signal. 2002;14(4):285-95.

18. Ono $\mathrm{H}$, et al. Regulation of phosphoinositide metabolism, Akt phosphorylation, and glucose transport by PTEN (phosphatase and tensin homolog deleted on chromosome 10) in 3T3-L1 adipocytes. Mol Endocrinol. 2001;15(8):1411-22.

19. B. Vanhaesebroeck and D. R. Alessi, "The PI3K-PDK1 connection: more than just a road to PKB.," Biochem J., vol. 346 Pt 3, pp. 561-576, 2000

20. Kang GG, Francis N, Hill R, Waters D, Blanchard C, Santhakumar AB. Dietary polyphenols and gene expression in molecular pathways associated with type 2 diabetes mellitus: A review. Int J Mol Sci. 2020;21(1) MDPI AG.
21. Ortega Á, Berná G, Rojas A, Martín F, Soria B. Gene-Diet interactions in type 2 diabetes: The chicken and egg debate. Int J Mol Sci. 2017;18(6) MDPI AG.

22. Olsen KS, Skeie G, Lund E. Whole-Blood Gene Expression Profiles in LargeScale Epidemiological Studies: What Do They Tell? Curr Nutr Rep. 2015;4(4) Current Science Inc:377-86.

23. McLaughlin T, Allison G, Abbasi F, Lamendola C, Reaven G. Prevalence of insulin resistance and associated cardiovascular disease risk factors among normal weight, overweight, and obese individuals. Metabolism. 2004;53(4):495-9.

24. MacLaren R, Cui W, Simard S, Cianflone K. Influence of obesity and insulin sensitivity on insulin signaling genes in human omental and subcutaneous adipose tissue. J Lipid Res. 2008:49(2):308-23.

25. Rajkovic N, et al. Relationship between obesity, Adipocytokines and inflammatory markers in type 2 diabetes: relevance for cardiovascular risk prevention. Int J Environ Res Public Health. 2014;11(4):4049-65.

26. Lizcano JM, Alessi DR. The insulin signalling pathway. Curr Biol. 2002;12(7): R236-8.

27. Hatting $M$, Tavares CDJ, Sharabi K, Rines AK, Puigserver $P$. Insulin regulation of gluconeogenesis. Ann N Y Acad Sci. 2018;1411(1):21-35

28. Liu X. Overstimulation can create health problems due to increases in PI3K Akt/GSK3 insensitivity and GSK3 activity. Springerplus. 2014;3(1):356

29. George AM, Jacob AG, Fogelfeld L. Lean diabetes mellitus: an emerging entity in the era of obesity. World J Diabetes. 2015;6(4):613-20.

30. Perry JRB, et al. Stratifying Type 2 Diabetes Cases by BMI Identifies Genetic Risk Variants in LAMA1 and Enrichment for Risk Variants in Lean Compared to Obese Cases. PLoS Genet. 2012;8(5):e1002741.

31. Gual P, Le Marchand-Brustel Y, Tanti J. Positive and negative regulation of glucose uptake by hyperosmotic stress. Diabetes Metab. 2003;29(6):566-75.

32. K. Morino, K. F. Petersen, and G. I. Shulman, "Molecular mechanisms of insulin resistance in humans and their potential links with mitochondrial dysfunction." "Diabetes, vol. 55 Suppl 2, pp. S9-S15, 2006

33. Nakashima N, Sharma PM, Imamura T, Bookstein R, Olefsky JM. The tumor suppressor PTEN negatively regulates insulin signaling in 3T3-L1 adipocytes. J Biol Chem. 2000;275(17):12889-95

34. Zhou J, et al. Inhibition of PTEN activity aggravates post renal fibrosis in mice with ischemia reperfusion-induced acute kidney injury. Cell Physiol Biochem. 2017:43(5):1841-54.

35. Yang J, Chen Q. The effects of acetylation of PTEN on hepatic gluconeogenesis. J Alzheimer's Dis Park. 2016;6(3):1-7.

36. Zhou J, et al. Inhibition of PTEN activity aggravates cisplatin-induced acute kidney injury. Oncotarget. 2017:8(61):103154-66.

37. Ryu D, et al. Endoplasmic reticulum stress promotes LIPIN2-dependent hepatic insulin resistance. Diabetes. 2011;60(4):1072-81.

38. Neto-Ferreira R, Rocha VN, Souza-Mello V, Mandarim-de-Lacerda CA, de Carvalho JJ. Pleiotropic effects of rosuvastatin on the glucose metabolism and the subcutaneous and visceral adipose tissue behavior in C57BI/6 mice. Diabetol Metab Syndr. 2013;5(1):32

39. Ye $Y$, et al. Phosphodiesterase-3 inhibition augments the myocardial infarct size-limiting effects of exenatide in mice with type 2 diabetes. Am J Physiol Circ Physiol. 2013;304(1):H131-41.

40. Gehart $H$, Kumpf $S$, Ittner A, Ricci R. MAPK signalling in cellular metabolism: stress or wellness? EMBO Rep. 2010;11(11):834-40.

41. Lawan A, et al. Hepatic mitogen-activated protein kinase phosphatase 1 selectively regulates glucose metabolism and energy homeostasis. Mol Cell Biol. 2015;35(1):26-40.

42. Schmoll D, et al. Regulation of glucose-6-phosphatase gene expression by protein kinase Balpha and the forkhead transcription factor FKHR. Evidence for insulin response unit-dependent and -independent effects of insulin on promoter activity. J Biol Chem. 2000;275(46):36324-33.

43. Lu M, et al. Insulin regulates liver metabolism in vivo in the absence of hepatic Akt and Foxo1. Nat Med. 2012;18(3):388-95.

44. Cho $\mathrm{H}$, et al. Insulin resistance and a diabetes mellitus-like syndrome in mice lacking the protein kinase Akt2 (PKB beta). Science. 2001;292(5522): $1728-31$.

45. Collins QF, Xiong Y, Lupo EG, Liu H-Y, Cao W. p38 mitogen-activated protein kinase mediates free fatty acid-induced gluconeogenesis in hepatocytes. J Biol Chem. 2006;281(34):24336-44.

46. Miao D, Tong X-K, Chan GK, Panda D, McPherson PS, Goltzman D. Parathyroid hormone-related peptide stimulates Osteogenic cell proliferation through protein kinase C activation of the Ras/mitogenactivated protein kinase signaling pathway. J Biol Chem. 2001:276(34): 32204-13. 
47. Santoleri D, Titchenell PM. Resolving the paradox of hepatic insulin resistance. Cell Mol Gastroenterol Hepatol. 2019;7(2):447-56.

48. Samuel VT, et al. Mechanism of hepatic insulin resistance in non-alcoholic fatty liver disease. J Biol Chem. Jul. 2004;279(31):32345-53.

49. Samuel VT, et al. Inhibition of protein kinase Cepsilon prevents hepatic insulin resistance in nonalcoholic fatty liver disease. J Clin Invest. 2007; 117(3):739-45.

50. Samuel VT, Shulman GI. The pathogenesis of insulin resistance: integrating signaling pathways and substrate flux. J Clin Invest. 2016;126(1):12-22.

51. Valenti $L$, et al. Increased expression and activity of the transcription factor FOXO1 in nonalcoholic Steatohepatitis. Diabetes. 2008;57(5):1355-62.

52. Pawlak DB, Kushner JA, Ludwig DS. Effects of dietary glycaemic index on adiposity, glucose homoeostasis, and plasma lipids in animals. Lancet. 2004; 364(9436):778-85.

53. Willett W, Manson J, Liu S. Glycemic index, glycemic load, and risk of type 2 diabetes. Am J Clin Nutr. Jul. 2002;76(1):274S-80S.

54. Surwit RS, et al. Stress management improves long-term glycemic control in type 2 diabetes. Diabetes Care. 2002;25(1):30-4.

55. Mechanick Jl. Metabolic mechanisms of stress hyperglycemia. J Parenter Enter Nutr. 2006;30(2):157-63.

56. Barth E, et al. Glucose metabolism and catecholamines. Crit Care Med. 2007; 35(9 Suppl):S508-18

57. Nonogaki K. New insights into sympathetic regulation of glucose and fat metabolism. Diabetologia. May 2000:43(5):533-49.

58. Eigler N, Saccà L, Sherwin RS. Synergistic interactions of physiologic increments of glucagon, epinephrine, and cortisol in the dog. J Clin Invest. 1979;63(1):114-23.

59. Chang J-S, et al. Pattern of stress-induced hyperglycemia according to type of diabetes: a predator stress model. Diabetes Metab J. 2013;37(6):475-83.

\section{Publisher's Note}

Springer Nature remains neutral with regard to jurisdictional claims in published maps and institutional affiliations.

Ready to submit your research? Choose BMC and benefit from:

- fast, convenient online submission

- thorough peer review by experienced researchers in your field

- rapid publication on acceptance

- support for research data, including large and complex data types

- gold Open Access which fosters wider collaboration and increased citations

- maximum visibility for your research: over $100 \mathrm{M}$ website views per year

At $\mathrm{BMC}$, research is always in progress.

Learn more biomedcentral.com/submissions 